\title{
Research on the operational modal testing of a structural laboratory through ambient excitation
}

\author{
Xiaomin Zhang ${ }^{1, \mathrm{a}}$, Jianqi Chen ${ }^{1, \mathrm{~b}}$, *Yong Sun ${ }^{1, \mathrm{c}}$ \\ ${ }^{1}$ Shandong Agricultural University Water Conservancy and Civil Engineering Colleges, Tai,an \\ 271018, China \\ a773939837@qq.com, ${ }^{\mathrm{b}} 1263475532 @ q q . c o m,{ }^{\mathrm{c} S u n y o n g @ s d a u . e d u . c n}$
}

\begin{abstract}
Keywords: operational modal; modal analysis; parameter identification;vertical irregularities; weak story.

Abstract. Modal parameter identification plays an important role in the dynamic performance evaluation and design of seismic structures. In this paper, we tested the large span space steel structure laboratory in a university, and then got modal parameters such as frequency and vibration mode based on the assumption of stationary random process. Compared the analysis results and the numerical results of the model show: the measured results are different from the theoretical results, the calculation period is about 2 times of the measured period, the actual stiffness of the structure is even larger; The measured damping ratio is lower than the specified value. The strength and stiffness of the structure are increased by setting up the filling wall, to a certain extent, it reduces the damage of the main structure, but the vertical arrangement of the structure led to significant increase in interlayer deformation, a weak layer, unfavorable to the earthquake, which should be avoided in the layout of the structure.
\end{abstract}

\section{Introduction}

Operational modal's analysis is a kind of modal parameter identification method that only based on structural response, compared to the traditional theory based on the finite element modal analysis and the experimental modal analysis based on excitation response, it has obvious advantages[1]. Compared with the theoretical modal analysis is more accurate. Despite the fact that the numerical analysis level of structural dynamic response has been significantly improved with the continuous development of computer technology, theoretical model and actual structure still differ a lot. According to the statistics, the calculation period is about 1.5-3 times of the measurement period[2]. Compared with the experimental modal analysis, operational modal's analysis do not suspend the normal use of the structure, without causing damage to structures, and more convenient fast, strong economy. Domestic and foreign scholars brought forward a lot of analysis methods of work modal, Liu Yufei [3] and others made classification and summary of 16 kinds of typical modal parameter identification methods .This is the foundation to accurately identify the modal parameters such as frequency, vibration mode for other structure dynamic characteristics research.

\section{Project Overview}

The structural laboratory of a university is a large span space steel structure, the construction area of above-ground part is $7132.8 \mathrm{~m} 2$, partial 6 , bottom two span, steel truss support structure, vertical irregular, complex structural system. The height of the building (from floor to roof) is $22.8 \mathrm{~m}$, and the underground part comprises the lower part of the structural laboratory reaction wall and the underground reservoir of the hydraulic engineering laboratory. The Top floor plan and arrangement of measuring points is shown in Figure 1. The structure profile is shown in figure 2. 


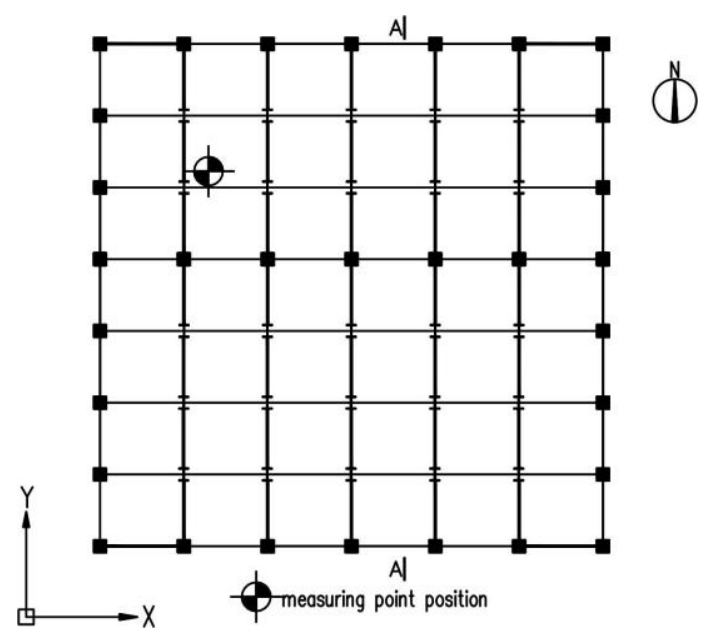

Fig.1 Top floor plan and arrangement of measuring points

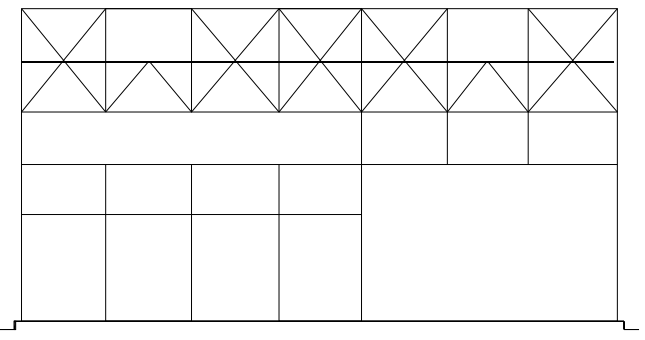

$\underline{A-A}$

Fig.2 Structure profile

\section{Test Principle and Modal Identification Method}

The modal parameter identification under ambient excitation can be simplified into a "excitation system - response" model. Known excitation and response, analyzing the modal parameters of the system are called system identification. At present, there are a lot of methods that regard the environmental excitation as random stationary signal, which is further considered as the Gauss white noise signal [4]. Therefore, the pulsation of the building is also a stationary stochastic process, ergodic property. Just make sure enough long test time,it can use a single sample function to describe all the features of random process, and clearly reflect the natural frequencies and natural vibration characteristics of the structure [5].

Based on the assumption of stationary random process, using the principle that the peak of frequency response function in the structure will appear in a certain order natural frequency,with random response power spectrum instead of frequency response functions, the structure natural frequency can identified from an peak of the average regularization power spectral density curve.

By random vibration theory, When a $\mathrm{N}$ degree of freedom system acts on $\mathrm{M}$ degrees of freedom, and there are the stationary random excitation $\{f(t)\}=\left\{f_{1}(t), f_{2}(t), \ldots, f_{m}(t)\right\}^{T}$, the power spectral density matrix relation between the stochastic acceleration response $\{a(t)\}$ and random incentive $\{f(t)\}$ is $\left[S_{a a}(\omega)\right]_{n \times n}=\left[H_{a}(\omega)\right]_{n \times m}\left[S_{f f}(\omega)\right]_{m \times m}\left[H^{*}{ }_{a}(\omega)\right]^{T}{ }_{m \times n}$. For smaller damping and frequency interval larger structure, under arbitrary random excitation, when $\omega=\omega_{i}$, thus $\frac{S_{\text {aapk }}\left(\omega_{i}\right)}{S_{\text {aapp }}\left(\omega_{i}\right)}=\frac{\phi_{k i}}{\phi_{p i}}$.

Type: $S_{\text {aapk }}(\omega)$ is the cross power spectrum density function of the system response between in $\mathrm{p}$ degree of freedom and the k degrees of freedom; $S_{\text {aapp }}(\omega)$ is the self power spectrum density function of the $\mathrm{P}$ degree of freedom response ; ${ }^{\phi_{i}}$ is the each order modal vectors of structure; $\omega_{\text {is circular }}$ frequency.

It regards peak ratio between cross power spectrum and self power spectrum that of response as approximate to vibration mode.This method can avoid bad input problem, and that,due to the use of relative relationship, it can improve signal-to-noise ratio in the processing of data[6]. 


\section{Structure Operational Modal Test and Analysis}

\section{Test Equipment and Test Process}

Using low frequency broadband vibration test system measures building pulsation response, the testing equipment mainly include four 941B sensors, a amplifier ,a Multi-channel signal acquisition instrument ,a laptop and some wireways.

First all, 4 sensors are placed in parallel in the top of structure to calibrate, and then respectively using $200 \mathrm{~Hz}$ and $80 \mathrm{~Hz}$ to test the structure, we can get different natural frequency and damping ratio in different sampling frequency of the structure, different sample frequencies have a great impact on the structural equivalent damping ratio. Referring to Ying Huaiqiao's study[7],for high sampling frequency,the resolution of the frequency is lower, damping ratio is bigger, and is not accurate enough. We Chose $80 \mathrm{~Hz}$ as reasonable sampling frequency. To appraise the stability of test results, We carried out several tests at $80 \mathrm{~Hz}$,obtaining fundamental frequency variance $2.14 \times 10-4$, and test results are basically stable.

The sensors are arranged in the stiffness center of each layer, site set up on the top floor, divided into 2 times test and recording, select 1 layer and 6 layer as a benchmark, first of all in 1 layer, layer 2 and layer 3, 6 layer setting $Y$ direction sensors to test $Y$ direction of the horizontal vibration, after completion of the test, the sensors counterclockwise direction of $90^{\circ}$ measuring $\mathrm{X}$ horizontal vibration. Then the 1 layer and 6 point unchanged, the measuring point in 4 and 5 layer test two directions of horizontal vibration.

Collect and record the test, each working condition of vibration for $20 \mathrm{~min}$.

\section{The Test Result and Analysis}

On September 10, 201623 PM to 2 AM the next day, we conducted field-test on the structural laboratory, the test result is shown in figure 3. Through processing the result of the test, We gained a rich supply of data that are the east-west and north-south forward three order natural frequency and damping ratio of the structure (see table 1), and we conclude that $\mathrm{X}$ and $\mathrm{Y}$ direction of one order translation mode of the structure (see table 2).
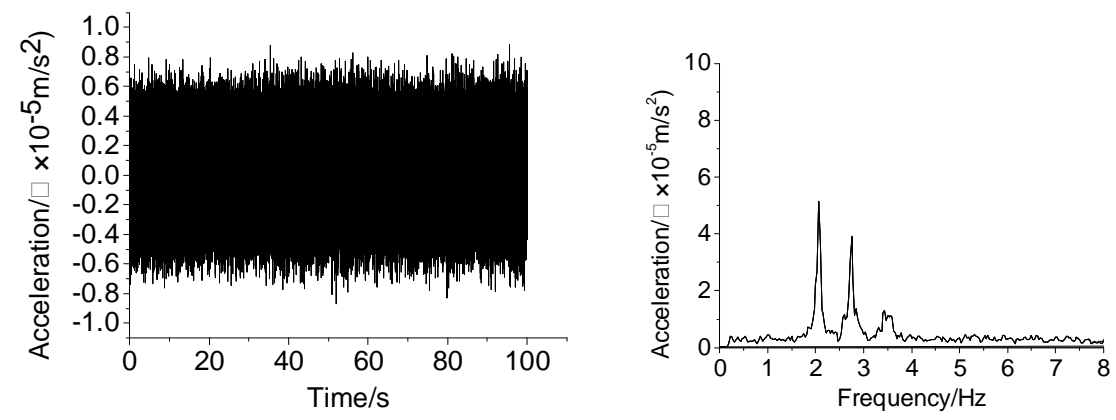

Fig. 3 The time history curves and frequency spectra of the 6 layers of the structure of the north and south of the structure

Test results show, that the first vibration mode of the structure is translational vibration in the $\mathrm{Y}$ direction, the second vibration mode is translational vibration in the $\mathrm{X}$ direction, and there is little difference in the two directions, the ratio of the longitude and transverse is 0.967.Comply with the requirement that the dynamic characteristics of the structure are similar in the two principal axes that is of the "seismic design code for buildings" (GB5001 - 2010) - 3.5.3.3, showing that the two direction 
stiffness distribute more uniform, and $\mathrm{X}$ direction stiffness slightly larger than $\mathrm{Y}$ direction stiffness. Because 2 layer that is a local sandwich with 3 layer together to form large space, the amplitude ratio is very close in the $\mathrm{Y}$ direction. The measured damping ratio are mainly distributed in the range of $1 \%$ to $4 \%$, the maximum is $3.83 \%$."Seismic design code for buildings" (GB5001-2010) - 8.2.2, The calculation of earthquake, when the height is not more than $50 \mathrm{~m}$, The damping ratio is 0.04 .The measured damping ratio is slightly lower than the specified value.

Table 1 Dynamic characteristics of measured structure

\begin{tabular}{c|c|c|c|c|c|c}
\hline \multirow{2}{*}{ Modal } & \multicolumn{3}{|c|}{ E-W } & \multicolumn{3}{c}{ N-S } \\
\cline { 2 - 7 } & $\begin{array}{c}\text { Natural } \\
\text { Frequency } \\
/ \mathrm{Hz}\end{array}$ & $\begin{array}{c}\text { natural } \\
\text { vibration } \\
\text { period/s }\end{array}$ & $\begin{array}{c}\text { damping } \\
\text { ratio } \\
/ \%\end{array}$ & $\begin{array}{c}\text { Natural } \\
\text { Frequency } \\
/ \mathrm{Hz}\end{array}$ & $\begin{array}{c}\text { natural } \\
\text { vibration } \\
\text { period/s }\end{array}$ & $\begin{array}{c}\text { damping } \\
\text { ratio } \\
/ \%\end{array}$ \\
\hline 1 & 2.135 & 0.469 & 1.35 & 2.062 & 0.485 & 2.27 \\
\hline 2 & 2.812 & 0.356 & 1.05 & 2.750 & 0.364 & 1.82 \\
\hline 3 & - & - & - & 3.437 & 0.291 & 3.83 \\
\hline
\end{tabular}

Note : The blank of the natural frequency is no obvious frequency in this direction.

Table 2 Structure of the first-order vibration mode

\begin{tabular}{|c|c|c|c|c|c|c|c|}
\hline \multicolumn{4}{|c|}{ E-W } & \multicolumn{4}{|c|}{$\mathrm{N}-\mathrm{S}$} \\
\hline $\begin{array}{c}\text { Frequency } \\
/ / \mathrm{Hz}\end{array}$ & Storey & $\begin{array}{c}\text { Amplitude } \\
\text { Ratio }\end{array}$ & Mode of vibration & $\begin{array}{c}\text { Frequency } \\
/ \mathrm{Hz}\end{array}$ & Storey & $\begin{array}{c}\text { Amplitude } \\
\text { Ratio }\end{array}$ & Mode of vibration \\
\hline \multirow{6}{*}{2.135} & 6 & 1 & \multirow{5}{*}{$\begin{array}{l}6 \\
5 \\
4\end{array}$} & \multirow{6}{*}{2.062} & 6 & 1 & \multirow{5}{*}{$\begin{array}{l}6 \\
5 \\
4 \\
3 . \\
2 . \\
1 .\end{array}$} \\
\hline & 5 & 0.6916 & & & 5 & 0.7751 & \\
\hline & 4 & 0.5559 & & & 4 & 0.6142 & \\
\hline & 3 & 0.3825 & & & 3 & 0.4430 & \\
\hline & 2 & 0.1782 & & & 2 & 0.4410 & \\
\hline & 1 & 0.0963 & 0 & & 1 & 0.0343 & 0 \\
\hline
\end{tabular}

\section{Model Comparison}

We analyzed the finite element model of the structure by SATWE software, and the software is simplified in modeling[8]. The equivalent mass of non-structural elements such as infilled wall is calculated, and the stiffness is not considered.And basic calculation and superstructure calculation belong to two sub modules.Load transfer of foundation and superstructure is only considered in computing,without considering interaction and so on. The results of SATWE analysis are shown in Table 3.

Compared the analysis results and the numerical results of the model show: The first order frequency is lower by calculation, and it is about the $1 / 2$ measured results. The fundamental frequency of the structure is more in line with the actual dynamic performance of the structure through field test and data analysis. Compared with the numerical results, the actual stiffness of the structure is even larger.A large number of experimental studies and theoretical analysis show that[9]-[11],infilled wall has a certain improvement on the stiffness of frame structure. The increased degree is affected by number of infilled walls, layout position,material type,the opening rate and wall and frame connecting structure.

Wu Yang' s study[11] on filling wall-frame structure in Wenchuan earthquake shows, the presence of infilled walls increases the stiffness of the structure and seismic action,but the wall can absorb and 
consume a large amount of seismic energy during the earthquake and reduce the damage of the main structure. Therefore infilled wall in frame has more advantages than disadvantages.Li Yingmin[9], Ye Lieping[12] also think that infilled wall reasonably as the first seismic fortification line of frame structure makes frame structure become seismic system with two seismic fortification lines that is beneficial to the seismic behavior of frame structure.

However, horizontal and vertical layout of infilled walls unevenly will be adverse to the frame structure seismic. Discontinuous arrangement along the height of infill walls can lead to stiffness mutation ,forming weak layer, under the action of strong earthquake, top and bottom of the frame column in the weak layer without walls may have severe plastic hinge damage,forming lateral mechanism to lead to collapse. Because of the need to use function, 1 to 3 layers of the structure is two across-large space, 4 to the top have a number of office space, leading to the vertical anti lateral member of the structure is discontinuous, 4 layer and above the floor arrange $\mathrm{H}$ Steel beam columns, as shown in figure 1, and arrange a large number of infill walls, 3 layer and below is empty, becoming weak positions. The coefficient of vertical irregular structure obtaining by the analysis of finite element modeling are shown in table 4.

Table 3 SATWE calculation results

\begin{tabular}{c|c|c|c|c|c|c|c}
\hline $\begin{array}{c}\text { mode of } \\
\text { vibration }\end{array}$ & $\begin{array}{c}\text { natural } \\
\text { vibration } \\
\text { period }\end{array}$ & $\begin{array}{c}\text { translational } \\
\text { coefficient } \\
(\mathrm{X}+\mathrm{Y})\end{array}$ & $\begin{array}{c}\text { torsion } \\
\text { coefficient }\end{array}$ & $\begin{array}{c}\text { mode of } \\
\text { vibration }\end{array}$ & $\begin{array}{c}\text { natural } \\
\text { vibration } \\
\text { period }\end{array}$ & $\begin{array}{c}\text { translational } \\
\text { coefficient } \\
(\mathrm{X}+\mathrm{Y})\end{array}$ & $\begin{array}{c}\text { torsion } \\
\text { coefficient }\end{array}$ \\
\hline 1 & 0.9258 & $1.00(0+1)$ & 0.00 & 4 & 0.2444 & $0.98(0+1)$ & 0.02 \\
\hline 2 & 0.8646 & $1.00(1+0)$ & 0.00 & 5 & 0.2051 & 0.03 & 0.97 \\
\hline 3 & 0.5830 & 0.01 & 0.99 & 6 & 0.1841 & 0.00 & 1.00 \\
\hline
\end{tabular}

Table4 Table of vertical irregular coefficient of floor

\begin{tabular}{c|c|c|c|c|c|c|c|c|c}
\hline Storey & Rat X & Rat Y & Ratio X & Ratio Y & Storey & Rat X & Rat Y & Ratio X & Ratio Y \\
\hline 1 & 1.6061 & 1.6690 & 0.74 & 0.73 & 4 & 1.7523 & 0.1823 & 1.05 & 0.59 \\
\hline 2 & 1.6173 & 0.4360 & 1.00 & 1.01 & 5 & 2.2635 & 2.6761 & 1.00 & 1.11 \\
\hline 3 & 2.2050 & 0.3021 & 1.61 & 1.54 & 6 & 1.000 & 1.000 & 1.00 & 1.00 \\
\hline
\end{tabular}

Note: Rat X, Rat Y: In the X direction or Y direction, the lesser between the ratio of the lateral stiffness of the tower and $70 \%$ of the lateral stiffness of the corresponding upper tower and the ratio of the lateral stiffness of the tower and the $80 \%$ of average lateral stiffness of the three towers.

Ratio X , Ratio Y : In the X direction or Y direction, the ratio of the bearing capacity between the layer and the upper layer.

The table 4 shows that, in the 1 layer, the bearing capacity of the structure is changed along the two principal axes, and in the $\mathrm{Y}$ direction, there are 3 layers of lateral stiffness irregularity.Under the effect of frequent earthquake,structure is in flexible working condition ,limiting "small earthquakes not bad" by limit value of elastic inter-layer displacement angle. We get the maximum inter-layer displacement angle curve by the finite element model to analyze(see figure 4 ).By the figure, the $\mathrm{X}$ direction maximum inter-layer displacement angle for $1 / 2864$, appeared in the middle and upper floors. Maximum inter-layer displacement angle curve in $\mathrm{Y}$ direction had a mutation in the central floor, maximum inter-layer displacement Angle is 1/2511, appeared in the three layers. The main reason is that the vertical irregular leading to structure stiffness mutation to form weak layer. It may become the energy accumulation site in the strong earthquake, and it is unfavorable to resist earthquakes. 

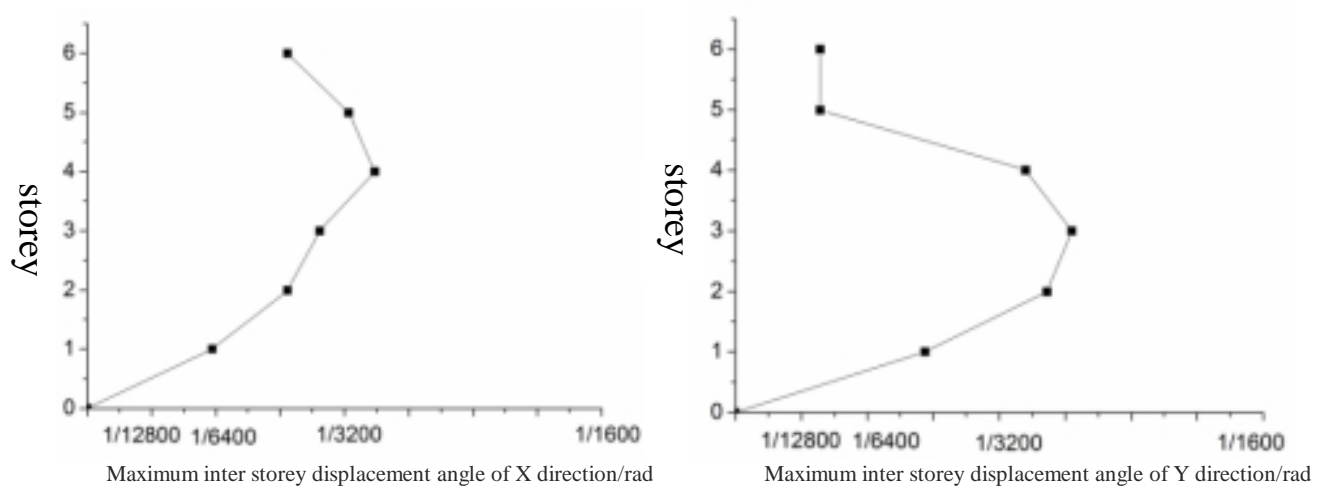

Fig.4 The maximum storey drift angle curve

\section{Conclusions}

At present, compared to the research abroad, there are not many measured data on the dynamic characteristics of civil buildings in china, the research is not deep enough. Based on the test and analysis of the large span steel structure, the following conclusions are obtained:

(1) The operating modal analysis and finite element modeling analysis for the steel structure indicate that the dynamic characteristics of the two methods are similar in the two main directions, but the measured results are different from the theoretical results, the calculation period is about 2 times of the measured period.Because there are a lot of simplified theoretical calculations, the actual stiffness of the structure is even larger.

(2) Structural damping ratio is generally obtained by measurement, the ambient excitation on site measurement is far less than the energy input of frequent earthquake. The measured damping ratio is lower than the specified value.

(3) Environmental excitation can not control the excitation energy, and it exists the problem of insufficient incentive. Therefore, it is difficult to identify the higher order modes, and identify the fine damage of the structure.

(4) The infilled wall in frame structure can increase the stiffness and strength of the structure at the same time. To a certain extent, it can reduce the main earthquake damage.But the vertical arrangement of the structure led to significant increase in inter-layer deformation, a weak layer, unfavorable to the earthquake, which should be avoided in the layout of the structure.

\section{Acknowledgements}

This work was financially supported by National Science and Technology Support Program( 2014DAL04B05 ) and Ministry of Construction Science and Technology Special( 2015K1040).

\section{References}

[1] Wang Z, Yan W M, Ye L P. J T singhua Univ (Sci \& Tech), 2011,51(6): 755 - 759.

[2] Fu Z C, Zhou D Y, Shi W X. Structural Engineers, 2014,30(2): 90 - 96.In Chinese.

[3] Liu Y F, Xin K G, Fan J S, et al. Engineering Mechanics, 2014,31(4): 46 - 52.

[4] Xu S D. Nanjing: South - East University, 2006.In Chinese.

[5] Shi W X, Wei D, Han R L. Journal of Earthquake Engineering and Engineering Vibration, 2012, 32(1):114-120. 
[6] Huang Y. Xian: Xi'an University of Technology, 2006.In Chinese.

[7] Ying H Q, Liu J M, Shen S. Noise and Vibration Control, 2006, 4(2):5 - 7.In Chinese.

[8] Tan D X, Zhou Y, Mi S T, et al. China Civil Engineering Journal, 2015,48(9): 41 - 50.

[9] Li Y M, Han J, Tian Q X, et al. Earthquake Engineering and Engineering Vibration, 2009, 29(3):51-58.

[10] Liu Y S, Li G Q. Journal of Building Structures, 2005, 26(3):78-84.In Chinese.

[11] Wu Y, Liu B K.Journal of Hefei University of Technology, 2010,33(9): 1372 - 1377.

[12] Ye L P, Lu X Z, Zhao S C , et al. Journal of Building Structures, 2009,30(6):67-76. 